\title{
Potential wine ageing during transportation
}

\author{
Rainer Jung, Bastian Leyh, Claus-Dieter Patz, Anne Rothermel and Christoph Schuessler \\ Hochschule Geisenheim University, Von-Lade-Strasse 1, 65366 Geisenheim, Germany
}

\begin{abstract}
In a global world, wineries have to satisfy the demand of consumers who wish to drink high quality wines from countries all over the world. To fulfill this request wines have to be transported, crossing thereby great distances from the place of production to the consumer country. At the Institute of Enology of Hochschule Geisenheim University examinations with White-, Rosé- and Red-Wines of different origins which had been transported over longer distances within Europe (Portugal, France, Italy to Germany) by trucks were carried out. Shipping of wines was simulated in a climatized cabinet to analyze the influence on wine quality during this way and conditions of transportation. Time and temperature profiles were based on real transport situtations which were recorded during shipping from Germany to Japan using data loggers. White, Rosé and Red wines were transported during 6 to 8 weeks and then were analytically and sensorically compared to those which were stored at a constant temperature of $15^{\circ} \mathrm{C}$. Besides the effect of temperature, the movements and vibrations encountered by the wines were also examined. Analytically wines were analyzed for general analytical parameters with Fourier-Transformation-Infrared-Spectroscopie (FTIR), Colour differences (Spectralphotometrie) and free and total sulfuric acid with Flow-Injection-Analysis (FIA). Sensory examinations with a trained panel were performed in difference tests in form of rankings and triangular tests. Summarizing the results from the different tests it could be found that transportation had an influence on the potential ageing of wines depending on the wine matrix. Especially high and varying temperatures during transportations over a longer distance and time had negative influences on wine quality. Also the movement of wine at higher temperatures had showed a negative effect whereas transport at cool temperatures even below $0{ }^{\circ} \mathrm{C}$ did not influence wine characteristics. Sophisticated, younger white and lighter wines with distinct levels of carbon dioxide showed tendencially clearer analytical and sensorical differences between transported and non-transported samples.
\end{abstract}

\section{Introduction}

Varying transport conditions of wine influence wine quality parameters to a different degree. Influencing parameters can be devided between endogenous and exogenous factors. Certainly endogenous factors as wine components (e.g. Oxygen, $\mathrm{CO}_{2}$-content, pH, polyphenols, microbiological and physical stability) determine the degree of possible damage under bad transport conditions. Moreover the avoidance of exogenous factors as humidity, pressure, light but especially transport temperature and time help to prevent wines from spoilage and could be controlled in the logistic chain.

Generally the transportation of bulk wine compared to the transport of bottled wine is recommended as being less harmful for wines which are transported over longer distances [1]. A sufficient content of $\mathrm{SO}_{2}$ is also necessary for wines which are exposed to higher temperatures during transportation. Colour of wines, unprotected by $\mathrm{SO}_{2}$ changed dramatically as well as the acetate esters became hydrolized during transportation at higher temperatures [2]. Ethyl carbamate was used as indicator substance in model wine solutions from Butzke (2011) to prove the negative effect on wines which were exposed to higher temperatures during transportation.
The bottle ageing effect of transportation at exposed temperatures was calculated between 1 and 18 months compared to conventional cellar storage [3].

The combined effect of storage (transportation) temperature and packaging on sensory, chemical and physical properties of Cabernet Sauvignon wine was analysed by Hopfer et al. (2013).

Increasing temperatures made the packaging effect more pronounced, the sensory panel found significant changes in aroma, flavor, taste, mouthfeel and colour attributes. Additionally changes in the polyphenol profile could be detected. Temperature exposed wines in bag-inbox packages showed the most signicant changes but at higher storage temperatures the wines from all packaging systems (glass bottles with different closures, Bag-inBoxes filled with different $\mathrm{O}_{2}$-Contents) showed oxidised characters [4].

In a literature study on the impact of shipping/transportation conditions and practices on wine [5] the optimization of packaging and shipping configurations are recommended as well as the establishment of guidelines for temperature survey (data loggers), temperature controlled containers and the preservation of control wine samples for reference. The study finishes also with the suggestion to evaluate possible effects of environmental 
Table 1. Transport data of wines by truck from Italy/Portugal to Germany.

\begin{tabular}{|l|l|l|l|l|l|l|}
\hline Wine & $\begin{array}{l}\text { Transport } \\
\text { via }\end{array}$ & $\begin{array}{l}\text { Transport } \\
\text { distance } \\
(\mathrm{km})\end{array}$ & $\begin{array}{l}\text { Transport } \\
\text { time }(\mathrm{h})\end{array}$ & $\begin{array}{l}\text { Min. } \\
\text { Temp. } \\
\left({ }^{\circ} \mathrm{C}\right)\end{array}$ & $\begin{array}{l}\text { Max. } \\
\text { Temp. } \\
\left({ }^{\circ} \mathrm{C}\right)\end{array}$ & $\begin{array}{l}\Delta \mathbf{t} \\
\approx\left({ }^{\circ} \mathrm{C}\right)\end{array}$ \\
\hline $\begin{array}{l}\text { Frizz. } \\
\text { Rosé }\end{array}$ & Express/Control & 1080 & 20,11 & 26,8 & 29,4 & 3 \\
\hline $\begin{array}{l}\text { Frizz. } \\
\text { Rosé }\end{array}$ & Truck & 1080 & 42,56 & 27,1 & 30,1 & 3 \\
\hline $\begin{array}{l}\text { Vinho } \\
\text { Rosé }\end{array}$ & Express/Control & 2125 & 26,50 & 22,7 & 25,8 & 3 \\
\hline $\begin{array}{l}\text { Vinho } \\
\text { Rosé }\end{array}$ & Truck & 2125 & 97,43 & 23,8 & 36,2 & 12 \\
\hline $\begin{array}{l}\text { Orvieto } \\
\text { DOC }\end{array}$ & Express/Control & 1020 & 24,30 & 22,3 & 26,9 & 5 \\
\hline $\begin{array}{l}\text { Orvieto } \\
\text { DOC }\end{array}$ & Truck & 1020 & 73,51 & 22,8 & 38,5 & 16 \\
\hline $\begin{array}{l}\text { Vinho } \\
\text { Branco }\end{array}$ & Express/Control & 2125 & 20,25 & 21,4 & 24,6 & 3 \\
\hline $\begin{array}{l}\text { Vinho } \\
\text { Branco }\end{array}$ & Truck & 2125 & 96,43 & 20,9 & 35,9 & 15 \\
\hline
\end{tabular}

conditions other than temperature which could influence wine quality during transportation.

At the Institute of Enology of Hochschule Geisenheim University examinations with White-, Rosé- and RedWines of different origins which had been transported over longer distances within Europe (Portugal, France, Italy to Germany) under realistic conditions by trucks were carried out. Shipping of wines was simulated in a climatized cabinet to analyze the influence on wine quality during this way and conditions of transportation. Time and temperature profiles were based on real transport situations which were recorded during shipping from Germany to Japan using data loggers. White, Rosé and Red wines were transported during 6 to 8 weeks and then were analytically and sensorically compared to those which were stored at a constant temperature of $15^{\circ} \mathrm{C}$.

Besides the effect of temperature, the movements and vibrations encountered by the wines were also examined.

\section{Material and methods}

\section{Transport of Wines within Europe by trucks}

Data shown in this article refers to wines of vintage 2012 which were transported by truck from Italy and Portugal to Germany during July 2013. Temperatures in the cases and transport times were documented with a data logger. The two wines from Italy came from Mareno di Piave/Treviso (I) and Bardolino/Verona to Essen (Ger). The wines from Portugal were transported from Avintes/Vila nova de Gaja (P) to Essen (Ger). The distance and time of transport as well as the temperature minimum and maximum during transportation by truck in comparison to express transports (control) are shown in Table 1.

\section{Shipment of Wines to Japan}

Two ship transports which had been documented before via data logger (EL-USB-2) from Germany to Japan were simulated with 5 different wines in a climatized cabinet

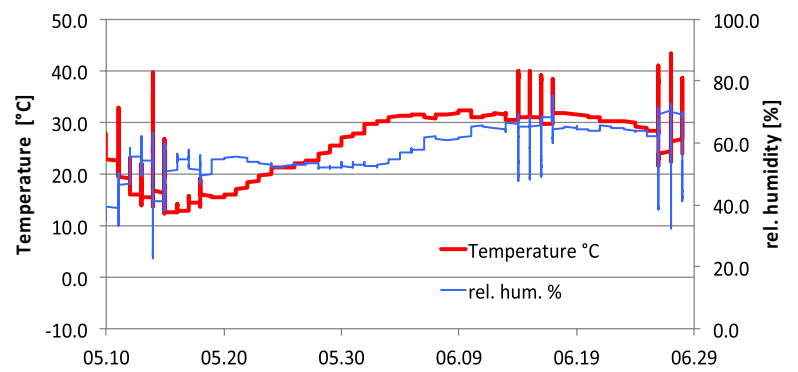

Figure 1. Transport 1, Shipment to Japan during Summer-Time (May/June), Temperature and air humidity profile.

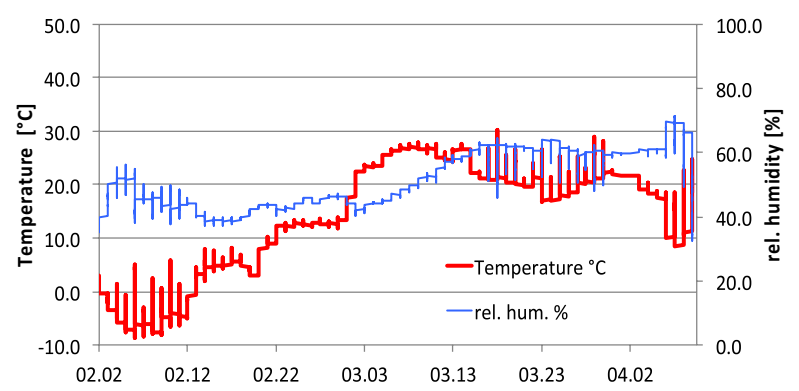

Figure 2. Transport 2, Shipment to Japan during Winter-Time (Feb-April), Temperature and air humidity profile.

(Memmert ICH 750) during transport times of 50 days (transport 1 , summer time, $\Delta \mathrm{t} \approx 30^{\circ} \mathrm{C}$ ) and 69 days (transport 2 , winter time, $\Delta \mathrm{t} \approx 40^{\circ} \mathrm{C}$ ). Temperature $\left({ }^{\circ} \mathrm{C}\right.$ ) and relative air humidity $(\%)$ had been documented and were simulated in the climate cabinet according to Fig. 1 (transport 1) and Fig. 2 (transport 2).

The wines which were exposed to the temperature profiles shown in Figs. 1 and 2 were wines which had been really transported from a german wine exporting company before. These were three german white wines (2012 Burg Layer Schlosskapelle, Kabinett, 2012 Nussdorfer Herrenberg, Müller-Thurgau QbA, 2011 Dienheimer Gueldenmorgen, Riesling Kabinett), one french rosé wine 


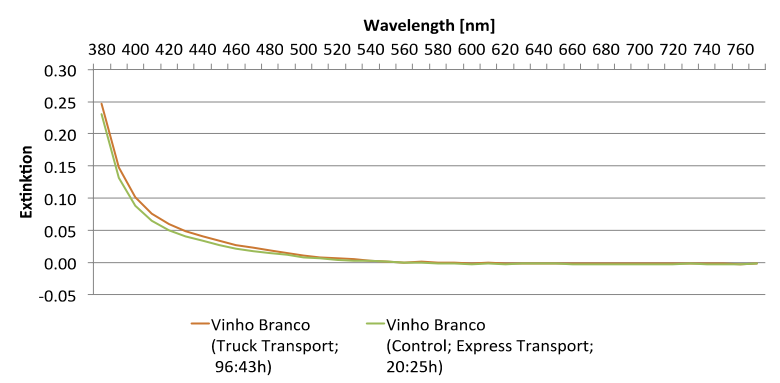

Figure 3. Colour in 2012 Vinho Branco (P) after transportation in Truck/Express from Portugal to Germany.

(2012 Chevalier de Bayard Rosé d'Oc) and one hungarian red wine (2012 Bor Forrás Cuvée Cabernet Sauvignon and Cabernet Franc, Prestige).

Beside the influence of temperature the effect of movement/non movement of wine during transportation should be analyzed. Therefore the wines of transport 1 and 2 (Figs. 1 and 2) were partly moved using a vibrating table with $100 \mathrm{Mot} / \mathrm{min}$ for 60 minutes. This movement was done three times during the whole transportation time of 50 or 69 days.

All wines (transports via truck and transports via ship in comparison to express or non transported wines) were analyzed with Forier-Transforming-InfraredSpectroscopie (FTIR) to get an overview on the main analytical parameters. Colour measurements were examined using a spectral photometer (Dr. Lange, Cadas 200). $\mathrm{SO}_{2}$ contents in all wine samples were analyzed via Flow injection analysis using a Foss FIAstar 5000.

Sensory effects on transported wines were measured using a panel of 22/23 trained tasters of Hochschule Geisenheim University. Sensory evaluations of the wines were done in difference ranking and triangle tests using FIZZ-Biosystemes software for design and statistical evaluations of the tests.

For all wine samples which came out of the shipping transport simulation leakage was observed by measuring the filling levels and weighing all bottles before, during and after the transport simulation. Further extraction forces for natural cork stoppers as well as cork weight and humidity were examined comparing samples with and without transport simulation.

\section{Results and discussion}

\section{Truck transport within European countries}

Analytical data for colour measurements with spectral photometrie in wine samples of 2012 Vinho Branco (P) and 2012 Orvieto (I) are shown in Figs. 3 and 4 and for 2012 Vinho Rosé (P) and 2012 Frizzante Rosé (I) in Figs. 5 and 6.

Comparing the colour changes in all analyzed wines it could be shown that the wines being transported over a longer distance from portugal (Vinho Branco, Vinho Rosé) changed colour significantly compared to the samples which were sent by express. This was not the case for the wines which were transported from Italy. For both wines, Orvieto and Frizzante Rosé the colour of the wines being

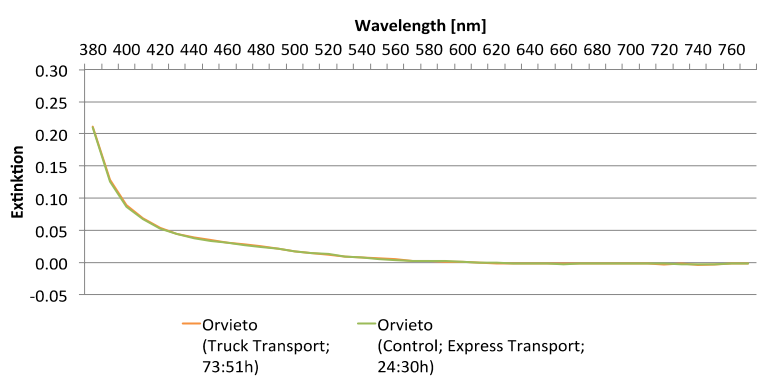

Figure 4. Colour in 2012 Orvieto (I) after transportation in Truck/Express from Italy to Germany.

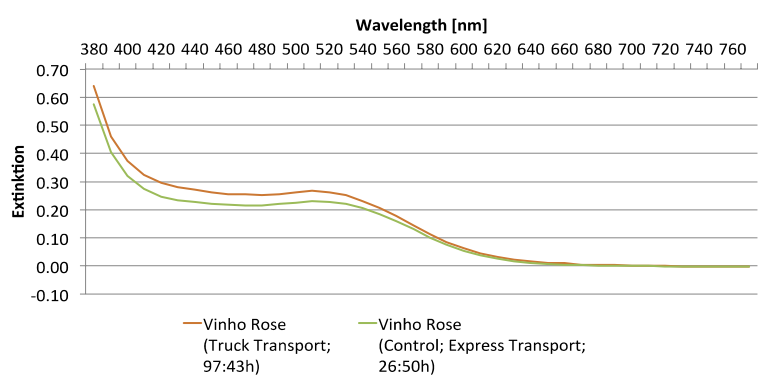

Figure 5. Colour in 2012 Vinho Rosé (P) after transportation in Truck/Express from Portugal to Germany.

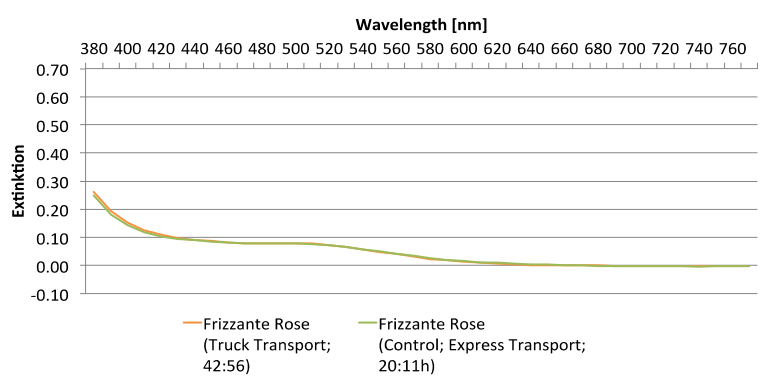

Figure 6. Colour in 2012 Frizzante Rosé (I) after transportation in Truck/Express from Italy to Germany.

transported in trucks was comparable to the colour of the express-samples.

Comparing this data with the transport times given in Table 1 transportation time and temperature difference during transportation seems to be responsible for the colour change in the wines coming from Portugal. Nevertheless the Orvieto from Italy also had a wide temperature variation during a long transport time and did not express a colour change compared to the expresssample.

Data from FIA measurements for free and total $\mathrm{SO}_{2}$ of 2012 Vinho Branco (P) and 2012 Orvieto (I) are shown in Fig. 7 and for 2012 Vinho Rosé (P) and 2012 Frizzante Rosé (I) in Fig. 8.

For all wines the analyzed $\mathrm{SO}_{2}$-contents were comparable between the samples which were more or less transported by truck compared to the express-samples.

Sensory evaluations of the transported wines in triangle tests revealed significant differences between the samples for 2012 Vinho Branco (P) and 2012 Vinho Rosé (P) of different transport conditions (truck vs. express). The result of an additional question concerning the preference 


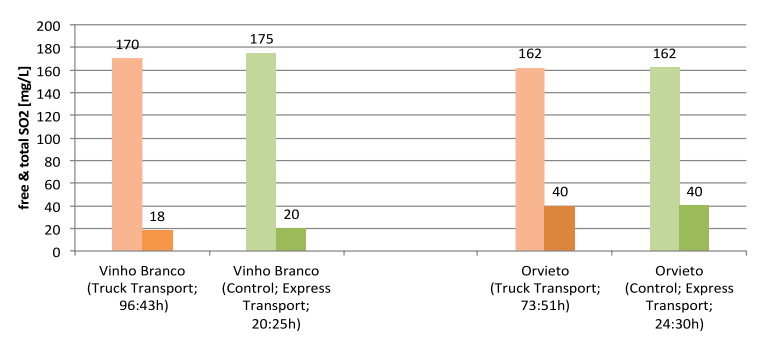

Figure 7. Free and total $\mathrm{SO}_{2}$ in 2012 Vinho Branco (P) and 2012 Orvieto (I) after transportation in Truck/Express from Portugal and Italy to Germany.

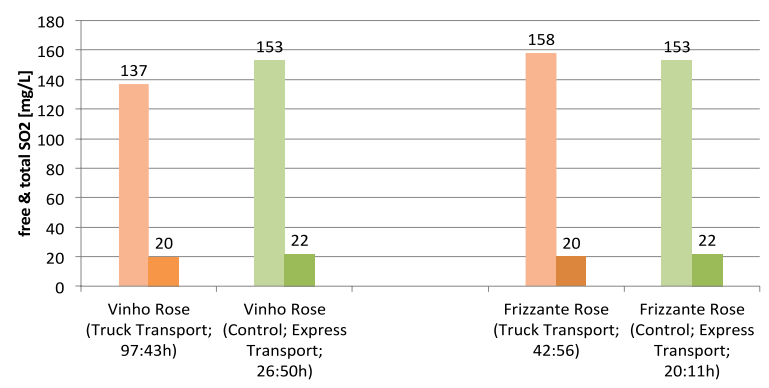

Figure 8. Free and total $\mathrm{SO}_{2}$ in 2012 Vinho Rosé (P) and 2012 Frizzante Rosé (I) after transportation in Truck/Express from Portugal and Italy to Germany.

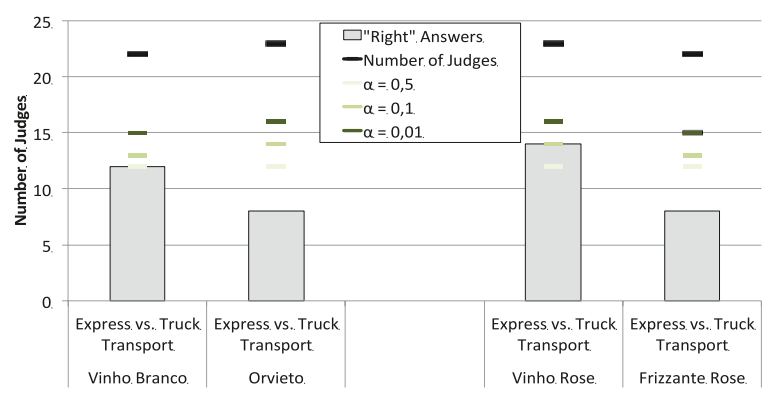

Figure 9. Sensory triangle difference tests with wines transported via Truck/Express from Portugal and Italy to Germany $(\mathrm{n}=$ 22/23 panelists)

for one of both samples was the positive discrimination of the express sample.

This was not the case for the wines 2012 Orvieto (I) and 2012 Vino Frizzante (I) because the panelists could not differenciate between the wines from the alternative transportation variants (Fig. 9).

\section{Shipment of Wines to Japan}

In Table 2 the results of FTIR measurements in the white wine "2012 Dienheimer Gueldenmorgen (DG)" are shown. This wine was taken examplarily and the analytical data of standard wine parameters shown in Table 2 indicates that no significant variation between the wines transported under different conditions (transport 1 and 2, movement/no movement) and control wine (storage under $15^{\circ} \mathrm{C}$ ).

Comparing the data for FIA-SO $\mathrm{S}_{2}$-measurements in the white wine "2012 Dienheimer Gueldenmorgen (DG)" it is obvious that the transported wines under "transport 1" (summer transport at higher temperatures) had only little lower contents of free and total $\mathrm{SO}_{2}$ after the transport

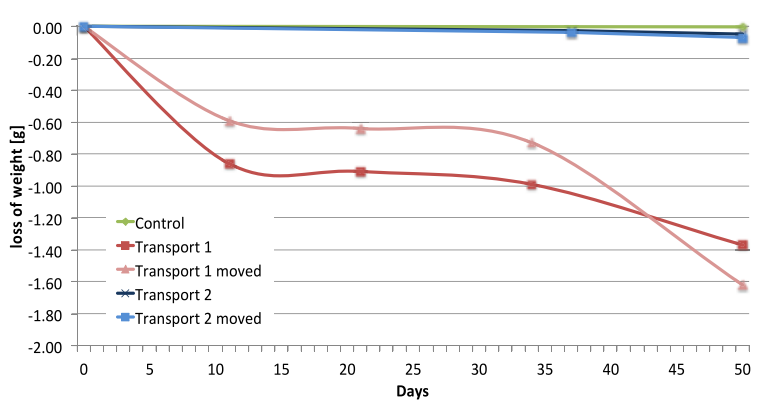

Figure 10. Loss of bottle weight (leakage) for samples of "2012 Dienheimer Gueldenmorgen" during transportsimulations with/without movement in a climatized cabinet (average of $n=$ 12 bottles).

simulation whereas the transport conditions 2 (winter transport at lower temperatures) did not show any variation compared to the control bottles stored constantly at $15^{\circ} \mathrm{C}$. Also the movement of bottles had no influence on the content of free and total $\mathrm{SO}_{2}$. In any case all wine samples of the different transport and movement variants had sufficient $\mathrm{SO}_{2}$ to protect the wines against oxidation (results in Table 3).

Figure 10 shows the results of weight measurements of bottles of "2012 Dienheimer Gueldenmorgen" which were stored under transport-simulations 1 and 2 with or without movement in comparison to control samples. It is obvious that the control bottles stored constantly at $15^{\circ} \mathrm{C}$ did not show any change in bottle weight during the storage as well as the bottles which were transported under condition 2 (winter transport). The bottles transported under condition 1 (summer transport) did lose weight (wine) especially during the first and last 10-15 days of transport. Comparing this data with the data shown in Fig. 1 it gets obvious that leakage of wine occured especially during time sequences when the bottles were stored in harbours or during transportations on trucks but not during shipment. The plot in Fig. 1 shows that the temperature inside the container alternated extremly between days and nights during the storage outside the ship. Obviously not the constantly increasing temperatures during the shipment but much more the extremly varying temperature movements during day and night outside the ship triggered leakage.

The described effect could also be documented for other wines under same transport conditions. Additionally cork humidity increased under these conditions which indicates also the effect of wine expansion (data not shown).

Figure 11 shows the data of sensory evaluation in a difference ranking test for "2012 Dienheimer Gueldenmorgen". The 23 panelists had the task to rank the five given samples (transports 1 and 2, each moved or not moved, control) according to freshness/fruitness of the sample. In this sensory evaluation the control sample (storage constantly at $15^{\circ} \mathrm{C}$ ) was judged to be the "freshest and fruitiest" wine. This sample could statistically not be differenciated from both samples of transport 2 (winter transport, with/without movement) and the sample without movement from transport 1 (summer 
Table 2. Analytical Data (FTIR) of standard wine parameters of "2012 Dienheimer Gueldenmorgen” from different transport simulations.

\begin{tabular}{|l|l|l|l|l|l|}
\hline $\begin{array}{l}\text { Sample/ } \\
\text { Parameter (g/L) }\end{array}$ & Control & $\begin{array}{l}\text { Transport 1 } \\
\text { (summer, } \\
\text { without } \\
\text { movement) }\end{array}$ & $\begin{array}{l}\text { Transport 1 } \\
\text { (summer, } \\
\text { with } \\
\text { movement) }\end{array}$ & $\begin{array}{l}\text { Transport 2 } \\
\text { (winter, } \\
\text { without } \\
\text { movement) }\end{array}$ & $\begin{array}{l}\text { Transport 2 } \\
\text { (winter, with } \\
\text { movement) }\end{array}$ \\
\hline Extract & 58,6 & 59,0 & 59,0 & 58,7 & 58,8 \\
\hline $\begin{array}{l}\text { Extract } \\
\text { sugar free }\end{array}$ & 20,6 & 21,0 & 21,1 & 21,0 & 20,9 \\
\hline $\begin{array}{l}\text { Extract } \\
\text { fermentable }\end{array}$ & 37,9 & 37,9 & 37,9 & 37,8 & 37,8 \\
\hline Glucose & 18,6 & 18,6 & 18,6 & 18,6 & 18,6 \\
\hline Fructose & 19,4 & 19,4 & 19,3 & 19,3 & 19,3 \\
\hline Total acidity & 7,2 & 7,2 & 7,2 & 7,2 & 7,2 \\
\hline pH & 2,82 & 2,83 & 2,84 & 2,84 & 2,84 \\
\hline Tartaric acid & 2,8 & 2,7 & 2,7 & 2,7 & 2,7 \\
\hline Malic acid & 2,9 & 3,0 & 3,0 & 2,9 & 3,0 \\
\hline Lactic acid & 0,6 & 0,6 & 0,7 & 0,6 & 0,6 \\
\hline Volatile acidity & 0,4 & 0,4 & 0,4 & 0,4 & 0,4 \\
\hline Citric acid & 0,4 & 0,3 & 0,3 & 0,3 & 0,3 \\
\hline Glycerol & 5,2 & 5,2 & 5,2 & 5,3 & 5,2 \\
\hline Alcohol & 68,1 & 67,8 & 68,1 & 68,4 & 68,1 \\
\hline
\end{tabular}

Table 3. Free and total $\mathrm{SO}_{2}$ (FIA) of "2012 Dienheimer Gueldenmorgen" from different transport simulations (average from $\mathrm{n}=$ 8 bottles per variant).

\begin{tabular}{|l|c|l|l|l|l|}
\hline $\begin{array}{l}\text { Sample/ } \\
\mathrm{SO}_{2}(\mathrm{mg} / \mathrm{L})\end{array}$ & Control & $\begin{array}{l}\text { Transport 1 } \\
\text { (summer, without } \\
\text { movement) }\end{array}$ & $\begin{array}{l}\text { Transport 1 } \\
\text { (summer, } \\
\text { with } \\
\text { movement) }\end{array}$ & $\begin{array}{l}\text { Transport 2 } \\
\text { (winter, } \\
\text { without } \\
\text { movement) }\end{array}$ & $\begin{array}{l}\text { Transport 2 } \\
\text { (winter, with } \\
\text { movement) }\end{array}$ \\
\hline Free $\mathrm{SO}_{2}$ & 38 & 34 & 34 & 38 & 39 \\
\hline Total $\mathrm{SO}_{2}$ & 148 & 132 & 138 & 145 & 148 \\
\hline
\end{tabular}

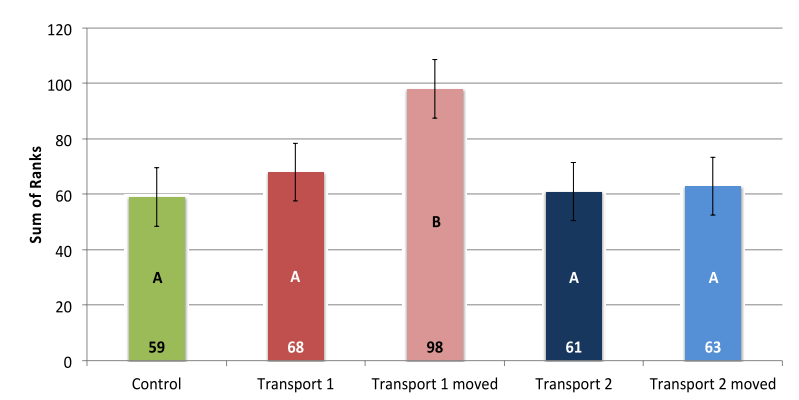

Figure 11. Sensory ranking tests with samples of "2012 Dienheimer Gueldenmorgen" after transportsimulations with/without movement in a climatized cabinet.

transport). Significantly less "fresh and fruity" was the judgement for the wine sample from transport 1 (summer transport) with movement. Obviously the movement of the wine under high and varying temperature transport conditions influenced the sensory characteristics whereas the analytical data was not influenced by this treatment.

\section{Conclusion}

Transport conditions for wine within Europe by truck did influence the colour and could trigger browning of wine and sensory deviations. Influencing parameters were time and temperature differences during transportation.
It could also be shown that wines react different under comparable conditions which indicates that the wine matrix (endogenous factors) influence the degree of deviations in wine quality.

Shipping of wine over longer distances was simulated in a climatized cabinet. Results of analytical and sensory examinations indicated that especially transports in summer time at higher temperatures had an negative impact on physical, chemical and sensorical properties of wine bottles. Especially changing temperatures between day and night but also movement of bottles at higher temperatures seem to influence wine quality whereas transport at cool temperatures even below $0{ }^{\circ} \mathrm{C}$ had no negative effect.

This ongoing work was financially supported by the "Ausschuss für Technik im Weinbau (ATW)”, Project No. 191.

\section{References}

[1] A. Hartley, Bulk shipping of wine and its implications for product quality, Wrap report, ISBN 1-84405-389X, 1-19 (2008)

[2] C. S. Ough, Some effects of temperature and $\mathrm{SO}_{2}$ on wine during simulated transport or storage, American Journal of Enology and Viticulture, Vol. 36, No. 1, 18$22(1985)$ 
[3] C.E. Butzke, E. E. Vogt, L. Chacón-Rodriguez, Effects heat exposure on wine quality during transport and storage, Journal of wine research, Vol. 23, No. 1, 1525 (2011)

[4] H. Hopfer, P. A. Buffon, S. E. Ebeler, H. Heymann, The combined effects of storage temperature and packaging on sensory, chemical and physical properties of Cabernet Sauvignon, Journal of Agricultural and food Chemistry, Vol. 61, 3320-3334 (2013)

[5] M. Meyer, A study of the impact of shipping/transportation conditions and practices on wine, Final Report, 1.3.1/702.0001, 1-42 (2002) 